\title{
Acknowledgment to Reviewers of Epidemiologia in 2021
}

\author{
Epidemiologia Editorial Office
}

Citation: Epidemiologia Editorial

Office. Acknowledgment to

Reviewers of Epidemiologia in 2021.

Epidemiologia 2022, 3, 40-41.

https://doi.org/10.3390/

epidemiologia3010004

Published: 27 January 2022

Publisher's Note: MDPI stays neutral with regard to jurisdictional claims in published maps and institutional affiliations.

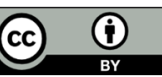

Copyright: ( 2022 by the author. Licensee MDPI, Basel, Switzerland. This article is an open access article distributed under the terms and conditions of the Creative Commons Attribution (CC BY) license (https://creativecommons.org/licenses/by/4.0/).

MDPI AG, St. Alban-Anlage 66, 4052 Basel, Switzerland

Rigorous peer-reviews are the basis of high-quality academic publishing. Thanks to the great efforts of our reviewers, Epidemiologia was able to maintain its standards for the high quality of its published papers. Thanks to the contribution of our reviewers, in 2021, the median time to first decision was 24 days and the median time to publication was 56 days. The editors would like to extend their gratitude and recognition to the following reviewers for their precious time and dedication, regardless of whether the papers they reviewed were finally published:

Alegria-Moran, Raul

Ali, Mohamed

Ali, Nowrouzi

Alsinglawi, Belal

Aquino, Antonio

Arteaga-Livias, Kovy

Asakura, Hiroshi

Aydin, Malik

Bartas, Martin

Bärwolff, Günter

Bukic, Josipa

Carbajo-Lozoya, Javier

Carnide, Filomena

Coro, Gianpaolo

Cruz-Fuentes, Carlos S.

D'Alessandro, Miriana

Dobrovolny, Hana M.

Dumetz, Franck

Eberl, Hermann J.

Ferorelli, Davide

Ferreira, Fernando

Foppa, Ivo M.

Gandolfi, Alberto

Geyer, Nathaniel

Gong, Wenping

Guest, Johnathan D.

Hair, Nicole L.

Hay, Roderick

Heber, Nielsen

Hinojo-Lucena, Francisco Javier

Hukowska-Szematowicz, Beata

Iboi, Enahoro A.

Ibrahim, Mahmoud
Kamp, Christel

Kimball, Ann Marie

Kraay, Alicia

Lancella, Laura

Li, Hao

Li, Liu

Liebherr, Magnus

Liu, George

Llarena, Ann-Katrin

Lorusso, Felice

Maglietta, Giuseppe

Maglitto, Fabio

Magori, Krisztian

Maharani, Asri

Martinez-Jarreta, Begoña

Miteva, Simona

Nitzan, Dorit

Olivares, Fernando

Padgett, Joshua Lee

Pantic, Igor

Punetha, Ankita

Rahmadani, Firda

Rahman, Hadiar

Ramanathan, Palaniappan

Ramkrishna, Doraiswami

Rana, Jyoti

Rao, Mana

Reid, St Patrick

Rouzine, Igor

Saito, Mayuko

Santamaría-Peláez, Mirian

Savini, Lara

Sawik, Tadeusz 
Shekhtman, Louis

Van Overmeire, Roel

Sundaram, Appavu K.

Varadarajan, Janani

Talakić, Emina

Vilinová, Katarína

Trevisan, Andrea

Willenberg, Holger

Tuomilehto, Jaakko

Yavuz, Mehmet

Umapathi, Krishna Kishore

Zhao, Bingchun 